\title{
Estimates of Maternal Mortality in Western Tanzania by the Sisterhood Method
}

\author{
Godfrey Mbaruku, ${ }^{1,2}$, Fred Vork, Dismas Vyagusa ${ }^{4}$, Rex Mwakipiti and Jos van Roosmalen ${ }^{6}$
}

\begin{abstract}
Maternal mortality in Kigoma Region, western Tanzania, was assessed as part of ongoing efforts to reduce maternal deaths in the area. A sisterhood survey was carried out using a questionnaire in which respondents were asked about their sisters who died during pregnancy, childbirth or within six weeks after childbirth. Three thousand and twenty nine individuals were interviewed. The overall estimated maternal mortality ratio (MMR) in Kigoma Region was 606 per 100,000 live births (95\% CI 518-695). In urban areas, the MMR was 447 (95\% CI 262-635), compared to 638 (95\% CI 539-737) in rural areas. The highest MMR of 757 was found in Kigoma rural district, the most isolated part of the region (95\% CI 599-916). Although the differences are not statistically significant, they may indicate poor accessibility as a risk factor. Maternal mortality in Kigoma is high when compared to other regions in Tanzania. The sisterhood method is relatively simple and convenient for estimating maternal mortality in resource-poor countries. (Afr J Reprod Health 2003; 7[3]: 84-91)
\end{abstract}

\section{RÉSUMÉ}

Estimations de la mortalité maternelle en Tanzanie de l'ouest à travers la méthode de recueillir des renseignements auprés des soeurs des femmes interviewees. Nous avons évalué la mortalité maternelle dans la région de Kigoma, en Tanzanie de l'ouest dans le cadre des efforts en cours vers la réduction des décès maternels dans la région. Une enquête basée sur les renseignements sur les soeurs des femmes interviewées a été menée à l'aide d'un questionnaire sur lequel les gens interviewés ont répondu aux questions portant sur leurs soeurs mortes pendant la grossesse, l'accouchement ou moins de six semaines après l'accouchement. Trois mille vingt-neuf individus ont été interviewés. Les estimations globales de rapport de la mortalité maternelle (RMM) dans la région de Kigoma était de 606 pour 100,000 naissances vivantes (95\% CI 262-635) par rapport à 638 (95\% CI 539-737) dans les régions rurales. Le RMM le plus élevé qui était de 757, a été trouvé dans le district rural de Kigoma qui est la partie la plus isolée de la région (95\% CI 599-916). Bienque les différences ne sont pas significatives du point de vue statistique, elles peuvent quand-même indiquer que le mauvais accès est un facteur de risque. La mortalité maternelle à Kigoma est élevée par rapport à d'autres régions en Zambie. L'approche basée sur les renseignement sur des soeurs est relativemnt simple et convenable pour l'évaluation de la mortalité maternelle dans les pays pauvres en ressources. (Rev Afr Santé Reprod 2003; 7[3]: 84-91)

KEY WorDs: Maternal mortality, sisterhood method, Tanzania

${ }^{1}$ Maweni Regional Hospital, Kigoma, Tanzania. ${ }^{2}$ Division of International Health (IHCAR), Karolinska Institutet Stockholm, Sweden. ${ }^{3}$ Department of Obstetrics and Gynaecology, Diaconessenbuis Leiden, The Netherlands. ${ }^{4}$ District Medical Office, Kigoma. ${ }^{5}$ Clinical Officers Training College, Kigoma. ${ }^{6}$ Department of Obstetrics, Leiden University Medical Centre, The Netherlands. 


\section{Introduction}

Despite the Safe Motherhood Initiative launched in 1987, the annual number of maternal deaths is estimated at 515,000, out of which $99 \%$ occur in low and middle-income countries. While the maternal mortality ratio, defined as the number of maternal deaths per 100,000 live births, has dropped to a level as low as 10 in the high income countries, it is over 1,000 in parts of Africa. ${ }^{1}$ Estimating maternal mortality in a community is notoriously difficult especially in low-income countries where vital statistics are often incomplete or do not exist and hospital data may not reflect the actual maternal risk in the community. ${ }^{2}$ Prospective population-based surveys will give the most accurate estimates but are difficult to organise, time-consuming and expensive. Indirect methods have been found to be more practical and less expensive. Graham et $\mathrm{al}^{3}$ developed an indirect method to assess the risk of maternal deaths, the sisterhood method, based on the sibling survivorship principle. The method proceeds by a gathering of retrospective information either from a population census or through sample surveys. The sibling survivorship method has been found to be the most precise in adult populations compared to the orphanage or widowhood methods. It involves only questions about whether the respondent has had any female siblings who died. ${ }^{4}$ This method has been validated several times. ${ }^{3-5}$

In Tanzania, the maternal mortality ratios (MMRs) differ substantially, ranging from 197 to 977 per 100,000 live births, depending on area and data sources. ${ }^{6}$ Four sisterhood method surveys have been undertaken. The reported MMRs were 297, 363534, 362-444, and 848-1044 per 100.000 live births respectively. ${ }^{5-8}$

Kigoma is a remote region in western Tanzania. In 1987, the region was among the three with the highest maternal mortality ratios in the country with an estimated MMR of 300 per 100,000 live births. The national figure by that year was 190 per 100,000 live births. ${ }^{9}$ The data was, however, hospital-based. Between 1984 and 1991 a progressive drop was seen in the regional hospital from the magnitude of 933 to 186 per 100,000 ive births. This was attributed to a comprehensive intervention programme from 1987-1991 that aimed at reducing substandard care at the hospital level. ${ }^{10}$ However, these achievements could not be sustained and by 1997 the hospital MMR was 400 per 100,000 live births.

\section{Materials and Method}

Kigoma region is a remote area of 37,000 square kilometres in western Tanzania with a population of 1.2 million inhabitants. The crude birth rate is 40 per 1,000 and the total fertility rate 6.3 per thousand. Therefore, 48,000 births are expected to occur in the region. However, only 9,000 are registered annually by the four facilities with comprehensive emergency obstetric care (this means the availability of basic obstetric care, operative delivery and blood transfusion). Another 7,000 are registered in rural health centres with basic emergency obstetric care facilities. The remaining 32,000 (66\%) women, therefore, deliver at home largely by themselves or assisted by untrained traditional birth attendants.

Data collection took place during a two-week period in October 2000. Twenty six students of the Kigoma Clinical Officers Training Centre were trained by the authors for two days for the survey. One afternoon was used for pre-testing of the questionnaire. The estimated number of interviews per student per day was between 20 and 25 and 10 minutes for each interview. Villages in each of the four districts were randomly sampled in proportion to the population. Villages were enumerated and sampling performed at the district headquarters involving the district medical personnel and administrators. From available data at the district headquarters the number of households per village was obtained. Depending on the population of each district, the average number of households to be interviewed per village was calculated. District leaders were informed and permission obtained. Supervisors were physically present during the actual interviews and cross-checked the questionnaires in the field. Both men and women who were present in the household at the time of the interview were included. Respondents had to be 15 years or older and were sub-divided into fiveyear groups, i.e., 15-19 years, 20-24 years, etc, up to 60 years and older.

The following four questions were asked: 
1. How many sisters do (did) you have of 15 years or older who were born to your own mother?

2. How many of these sisters are still alive?

3. How many of these sisters have died?

4. How many of these sisters who died, died during pregnancy, childbirth or within six weeks after childbirth?

The first question defines the total number of women ever at risk of maternal death, while the fourth question gives the total number of maternal deaths in this group.

Since respondents were asked about sisters born to their own mother, we excluded the so-called extended family. Interviewers were urged to check whether the sum of answers to questions 2 and 3 were equal to question 1. Data were processed according to the method described by Graham et al. ${ }^{3}$ Details of the method will be presented together with the results, since the figures will facilitate explanations.

There is a relationship between the number of interviews held and the margin of error of the calculated maternal mortality ratio. Also, the expected level of maternal mortality is inversely related to the number of interviews needed. If maternal mortality is expected to be low, one will need a large number of interviews to achieve a reliable estimate. According to the method of Hanley et al, ${ }^{11}$ in case the expected MMR is between 500 and 750, between 2,100 and 3,200 interviews are needed to achieve a margin of $\pm 20 \%$ error. To achieve a margin of \pm $10 \%$ error one would need 8,000-13,000 interviews. These large numbers were not feasible in our setting and, therefore, we chose to interview 3,000 people, aiming at a margin of $20 \%$ error.

Two adjustments were to be made:

1. Due to the fact that respondents of 15-19 and 20-24 years old still have other sisters not yet 15 years of age at the time of the survey, the actual number of reported sisters by those younger respondents will underestimate this number. Therefore, the hypothetical number of sisters ever to be at risk in these younger respondents groups should be calculated based on the average number of sisters reported by the older respondents (those above 25 years).
2. Respondents of 60 years or older would be able to provide information about sisters who, on average, have been exposed to full time risk. Younger respondents would give information about sisters who have been exposed for only part of their reproductive life to the risks of maternal death. Multiplication of the reported number of sisters (column 3 of Table 1) with an adjustment factor (column 5 ) gives the socalled sister units of risk exposure (column 6). This adjustment is based on the age distribution pattern of developing countries. ${ }^{3,12}$ In these countries where fertility is generally high, the age scale has to be transformed as originally suggested by Brass in order to be representative. ${ }^{12}$ The age distribution of the study population in Kigoma was typical of this pattern and, therefore, this adjustment was mandatory. The transformed model is equivalent to Gompertz's model in which the natural age scale is replaced by a transformed one such that the observed fertility is related to a typical pattern of fertility. ${ }^{13}$

The lifetime risk (LTR), i.e., the risk of a woman dying from maternal causes during the whole of her reproductive life, can then be calculated using the following formula:

$$
\text { LTR }=\frac{\text { Total number of maternal deaths }}{\text { Total sister units of risk exposure }}
$$

With TFR, LTR may be translated into MMR using the following formula:

$$
\text { MMR }=(1-[(1-\mathrm{LTR}) 1 / \mathrm{TFR}] \times 100,000
$$

95\% confidence intervals were calculated using the method of Hanley et al.

\section{Results}

In total, 3,029 people were interviewed. The actual number of sisters reported by respondents of age groups 15-19 and 20-24 years were 578 and 1,811 respectively. However, these respondents could be expected to have sisters about to become 15 years. For the calculation, it was necessary to use the 
ultimate number of sisters ever to be at risk (aged more than 25 years). This average was 3.34 in our group. The number of respondents in the first two age groups was therefore multiplied by 3.34 in order to get the estimated ultimate number of sisters ever to be at risk. These estimated numbers were 725 and 2,061 respectively (Table 1 ).

Table 1 Maternal Mortality Estimates in Kigoma Region: Sisterhood Survey, 2000

\begin{tabular}{lccccr}
\hline $\begin{array}{l}\text { Age group } \\
\text { (years) }\end{array}$ & $\begin{array}{c}\text { Number of } \\
\text { respondents }\end{array}$ & $\begin{array}{c}\text { Sisters reaching } \\
\text { 15 years }\end{array}$ & $\begin{array}{c}\text { Maternal } \\
\text { deaths }\end{array}$ & $\begin{array}{c}\text { Adjustment } \\
\text { factor }\end{array}$ & $\begin{array}{c}\text { Sister units of } \\
\text { risk exposure }\end{array}$ \\
\hline $15-19$ & 217 & 725 & 6 & 0.107 & 78 \\
$20-24$ & 617 & 2,061 & 25 & 0.206 & 425 \\
$25-29$ & 626 & 1,982 & 20 & 0.343 & 680 \\
$30-34$ & 538 & 1,836 & 33 & 0.503 & 924 \\
$35-39$ & 473 & 1,637 & 41 & 0.664 & 1087 \\
$40-44$ & 281 & 1,003 & 29 & 0.802 & 804 \\
$45-49$ & 138 & 458 & 11 & 0.900 & 412 \\
$50-54$ & 81 & 245 & 8 & 0.958 & 235 \\
$55-59$ & 25 & 75 & 2 & 0.986 & 74 \\
$60+$ & 33 & 97 & 6 & 1.000 & 97 \\
\hline Total & 3,029 & 10,119 & 181 & & 4816 \\
\hline
\end{tabular}

Table 2 Sisterhood Studies for Tanzania and other various areas

\begin{tabular}{|c|c|c|c|c|}
\hline Author & Year & Location & MMR & $95 \% \mathrm{CI}$ \\
\hline Current study & 2000 & (Kigoma) Tanzania & 606 & $518-695$ \\
\hline $\operatorname{Lech}^{2}$ & 2002 & Swaziland & 229 & - \\
\hline Francesconi $^{8}$ & 2001 & (Iringa) Tanzania & 946 & 848-1044 \\
\hline Smith $^{72}$ & 2001 & (Brong-Ahafo) Ghana & 269 & - \\
\hline Font $^{6}$ & 2000 & (Ifakara) Tanzania & 448 & $363-534$ \\
\hline $\mathrm{Olsen}^{7}$ & 2000 & (Haydom) Tanzania & 362 & $269-456$ \\
\hline Orach $^{29}$ & 2000 & (Gulu ) Uganda & 662 & $421-839$ \\
\hline Garenne $^{15}$ & 1997 & (Nouna) Burkina Faso & 498 & 285-1135 \\
\hline Danel $^{25}$ & 1996 & Nicaragua & 243 & - \\
\hline Mace $^{31}$ & 1996 & (Turkana) Kenya & 599 & $424-775$ \\
\hline $\mathrm{Le} \mathrm{Bacq}^{21}$ & 1995 & (Kaputa) Zambia & 1,549 & $1427-1670$ \\
\hline Vork $^{28}$ & 1994 & (Kalabo) Zambia & 1,238 & - \\
\hline Hernande $z^{30}$ & 1994 & (Morelos) Mexico & 186 & $157-215$ \\
\hline Walraven $^{5}$ & 1994 & (Sumve) Tanzania & 297 & - \\
\hline Wirawan ${ }^{4}$ & 1994 & (Bali) Indonesia & 331 & - \\
\hline Oosterhuis $^{32}$ & 1993 & Zimbabwe & 316 & - \\
\hline Shiferaw $^{23}$ & 1993 & (Illubabor) Ethiopia & 570 & - \\
\hline Chiphangwi $^{24}$ & 1992 & (Thyolo) Malawi & 409 & - \\
\hline Graham $^{3}$ & 1986 & (Farafenni) Gambia & 1,005 & - \\
\hline
\end{tabular}


A second adjustment was needed since only respondents aged 60 years or older would provide information about sisters who, on average, have been exposed to a full-time risk. The reported number of sisters (column 3) gave the so-called sister units of exposure (column 6) by multiplying with the adjustment factor (column 5).

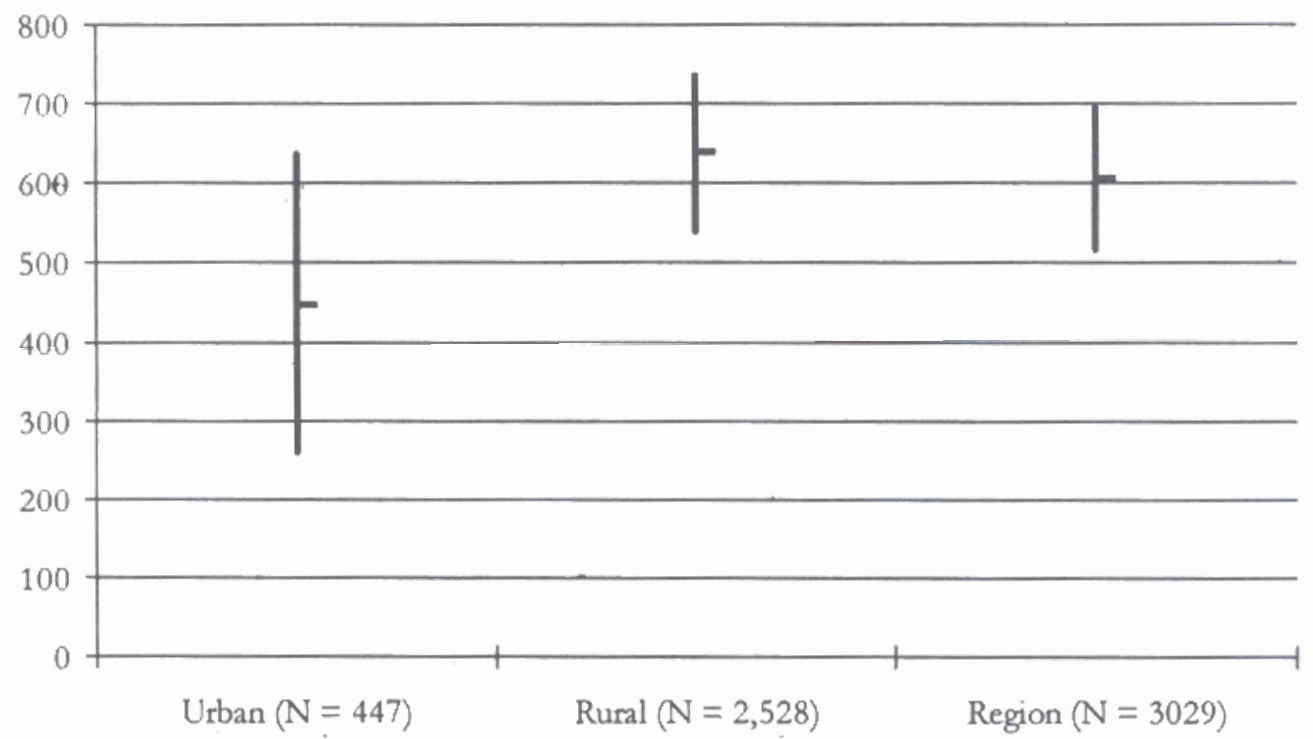

Figure 1 Estimates of Maternal Mortality Ratios in Kigoma Urban and Rural Areas (Mean Values with 95\% Confidence Intervals)

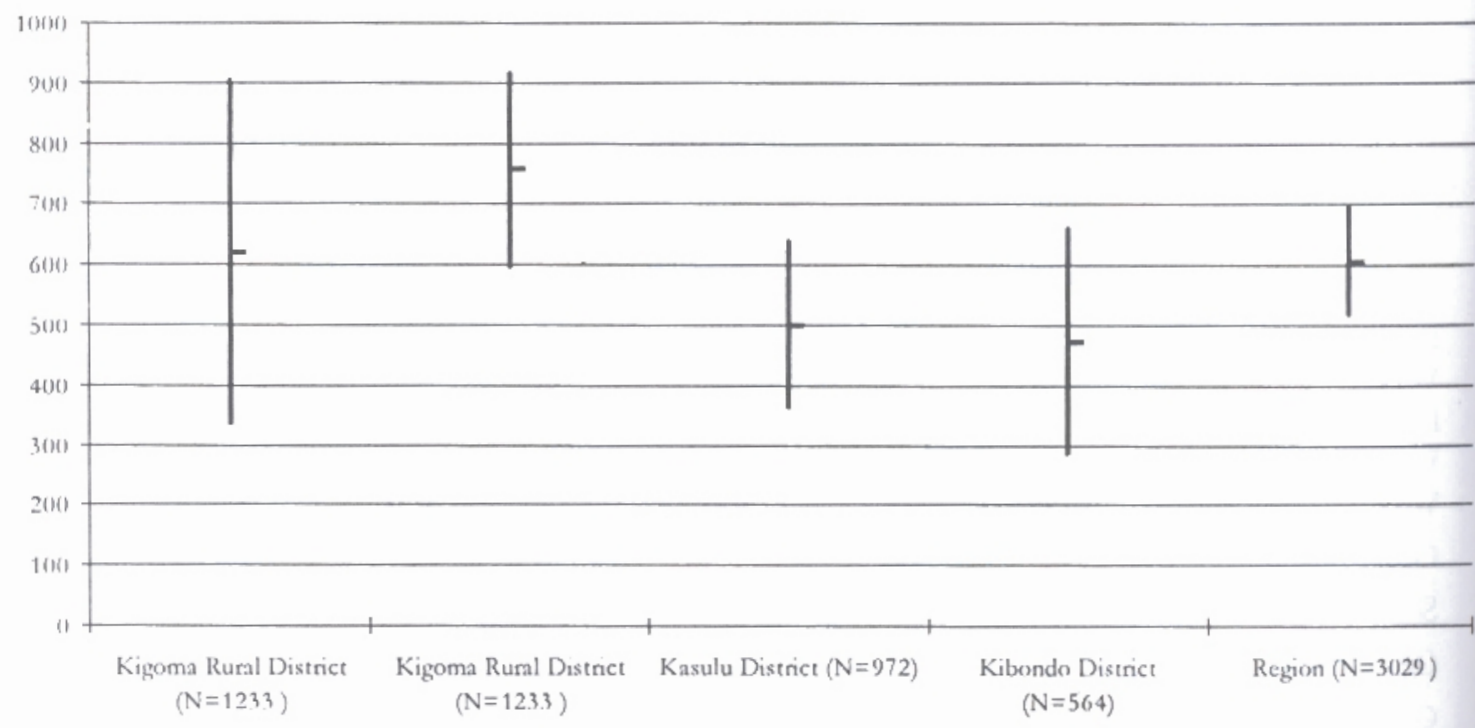

Figure 2 Estimates of Maternal Mortality Ratios in Kigoma by Districts (Mean Values with $95 \%$ Confidence Intervals) 
In our survey, LTR was $181 / 4,815=0.0376$, or approximately a $3.8 \%(95 \%$ CI $3.2-4.3)$ chance to die from maternal causes during reproductive life. This gave an estimated MMR of 606 (95\% CI 518695) per 100,000 live births for Kigoma region as a whole.

We divided the respondents into an urban and a rural group, the latter with poor accessibility to hospital facilities (Figure 1). The MMR in the urban group was 447 (95\% CI 262-635) and 638 (95\% CI 539-737) in the rural group. When we divided the region into districts, it was found that the MMR was highest in Kigoma rural district, which was the area with the poorest accessibility to health care (Figure 2).

\section{Discussion}

The sisterhood method was selected in this study due to the advantages of small sample size and low cost. It also requires short periods of time to undertake. In our situation, data collection took two weeks and analysis only a few days. However, the major disadvantages of the method must be considered as well, which inciude possible variations in the fertility rate.

In 1990, the contraceptive prevalence of Kigoma region was below $5 \%$. A drop in fertility rate will cause the estimation of MMR to fall. The phenomenon has been noted in high income countries such as Sweden where fertility patterns were studied covering the period 1870/1-1915/16 at five-year intervals. ${ }^{14} \mathrm{~A}$ fall in fertility will also affect the calculation of LTR, since the number of reported sisters in the youngest age groups are adjusted and, hence, may lead to overestimating LTR. In our study, however, MMR among respondents of 2549 years was between 459 and 646 per 100,000 live births (mean 552), which is not significantly different from the MMR of the whole group.

The second disadvantage is the lag period of the estimates. The method gives an estimate dating $10-12$ years before the survey. This fact is important in our study because in 1991 the hospital mortality was reduced to 183 per 100,000 live births, but we needed to know the real situation in the surrounding district at that time. We could not undertake the exercise at that time due to lack of resources. ${ }^{10}$
There have also been some doubts regarding the accuracy of the method, since the original method was based on a number of hypotheses such as the similarity of age differences in all populations and independence between the mortality of siblings. ${ }^{15}$ More complications arose from the various options in the method. For example, one can decide among the options "ever-married respondents" or "respondents aged 15 years and older", "ever married sisters" or even male and female respondents. The method was originally based on the sibling survival techniques that were extrapolated into the various age groups in order to describe mortality in areas where original data was either difficult to obtain or non-existent. ${ }^{16}$ In our study, we interviewed respondents aged 15 years and older only in order to have consistency in responses. Trussel and Rodriguez thoroughly reviewed the mathematical proof of the siblings issue and reached the conclusion that the key assumption of the method is independence of the mortality experiences of adult sisters. ${ }^{20}$ The method also underestimates early pregnancy deaths due to abortions and ectopic pregnancies, although in our study some interviewees specifically mentioned abortion in a few questionnaires. Furthermore, even suicides and homicides have recently been shown to be related to the pregnant state, hence, implying the inclusion of these conditions in the definition of a maternal death. However, this misclassification occurs also in high income countries that have elaborate systems of classifying maternal deaths such as France, ${ }^{1}$ the United States ${ }^{19}$ and The Netherlands. ${ }^{33}$

In Tanzania, four sisterhood surveys have been documented. ${ }^{5.8}$ Other studies have been done in other countries (Table 2). Inconsistency of reporting is noted, however, when confidence intervals were not calculated in all studies. ${ }^{2,5,27}$ Due to the wide confidence intervals of the method, it is mandatory to report thesi and to keep in mind the fact that the results do not indicate definite point estimates. Therefore, the method cannot be used to compare magnitudes of maternal mortality between countries and even different areas of the same country. ${ }^{18}$

Although statistically not significant, we found a higher MMR in areas with poorer accessibility. This agrees with other findings in Tanzania ${ }^{7}$ and 
Zambia. ${ }^{21,28}$ Distance has been found to be a major factor in the delay to reach care and even decision to go for care. ${ }^{22}$ A large area of Kigoma rural district is isolated and pregnant women have to overcome enormous physical barners, unlike the other districts, before they can reach the regional hospital in the main town. And in this Kigoma rural district we found the highest MMR of the whole region to be 757 (95\%CI 599-916 per 100.000 live births).

We had estimated from the population that, given the MMR (which actually refers to a period of 10 years previously), 300 matemal deaths would have been expected in the region. However, only 40 are presently reported in the official statistics. These findings imply that there is gross under-reporting of maternal deaths in the population. This was confirmed by the fact that in the same year, traditional birth attendants had reported a total of 50 maternal deaths in Kigoma rural district alone. Furthermore, our results are much higher than the official figures from health institutions even if one considers the period 10 years back (Figure 1).

Since health workers were involved in this survey the findings stimulated debate and a better comprehension of the problem of maternal mortality, its underestimation and where most deaths usually take place. This gave an opportunity for local leaders, staff and medical students, who are expected to work in rural areas after their training, to refocus efforts towards interventions aimed at reducing maternal mortality.

The goal of the safe motherhood initiative was to reduce maternal mortality by $50 \%$ by the year 2000 . However, recent reviews have shown that no change has occurred and there is little hope that any major reduction will occur in the foreseeable future. ${ }^{18}$ The knowledge of levels of maternal mortality are necessary not only for international comparisons but also for the planning of programmes, interventions and advocacy.

In conclusion, we have found the sisterhood method a valuable tool for estimating maternal mortality as well as planning interventions for the reduction of maternal mortality. The method gave impetus and directions on where to place more emphasis on envisaged programmes for ongoing efforts geared towards the reduction of this calamity.

\section{Acknowledgments}

We wish to thank the principal of the Clinical Officers Training College, Maweni, Kigoma, and the year 2000 final year students for facilitation and data collection respectively. We also thank the district administrative and medical authorities for their cooperation, and all citizens of the four districts for participating in the study. Finally, we wish to extend our sincere gratitude to the Dutch Obstetric and Family Planning Society and UNICEF country office for financial assistance.

\section{REFERENCES}

1. Hill $K$, AbouZahr $C$ and Wardlaw $T$. Estimates of maternal mortality for ${ }^{4} 995$. Bull World Health Org 2001; 79: 182-193.

2. Lech $M$ and $Z$ wane A. Survey on maternal mort ality in Swaziland using the sisterhood method. Paediatr Perinat Epidemiol 2002; 16: 101-107.

3. Graham W, Brass W and Snow RW. Estimating maternal mortality: the sisterhood method. Stud Fam Plann 1989; 3: 125-135.

4. Wirawan DN and Linnan M. The Bali indirect maternal mortality study. Stud Fam Plann 1994; 5 : 304-9.

5. Walraven GEL, Mkanje RJB, van Roosmalen J, van Dongen PW and Dolmans WM. Assessment of maternal mortality in Tanzania. BrJ Obstet Gynaecol 1994; 101: 414-417.

6. Font F, Alonso Gonzalez M, Nathan R, Lwilla F, Kimario J and Tanner M. Maternal mortality in a rural district of southeastern Tanzania: application of the sisterhood method. Int J Epidemiol 2000; 29: 107-112.

7. Olsen BE, Hinderaker SG, Kazaura M, et al. Estimates of maternal mortality by the sisterhood method in rural northern Tanzania: a household sample and an antenatal clinic sample. BrJ Obstet Gynaecol 2000; 107: 1290-97.

8. Francesconi $P$ and Pisani V. Estimating maternal mortality by the Sisterhood method in Iringa District, Tanzania. Trop Doc 2001; 31: 220.

9. MCH Unit, Ministry of Health. 1987 Tanzania Government document.

10. Mbaruku $G$ and Bergstrom S. Reducing maternal mortality in Kigoma, Tanzania. Health Policy Plann 1995; 10: 71-78. 
11. Hanley JA, Hagen CA and Shiferaw T. Confidence intervals and sample-size calculations for the sisterhood method of estimating mate mal mortality. Stud Fam Plann 1996; 27: 220-227.

12. Brass W. Methods of Estimating Fertility and Mortality from Limited and Defective Data. Chapel Hill: International Program for Population Statustics, 1975.

13. Booth, H. Transforming Gompertz's functions for fertility analysis: the development of a standard for the Relational Gompertz function. Pop Stud 1984; 38: 495-506.

14. Statistiska Centralbyran. Fertility for Birth Cohorts of Suedish Women, 1870-1940. Stockholm: Statistiska Centralbyran, 1969.

15. Garenne $\mathrm{M}$ and Friedberg F. Accuracy of indirect estimates of matemal mortality: a simulation Model. Stud Fam Plann 1997; 28: 132-142.

16. United Nations, Department of Economic and Social Affairs. Methods of estimating basic demographic measures from incomplete data. Manuals on Methods of Estimating Population. Manual 4. New York: United Nations, 1967.

17. Abou Zahr C and Royston E. Maternal Mortality. $A$ Global Fact Book. Geneva: World Health Organization, 2001.

18. World Health Organisation-UNICEF. The sisterbood Method for Estimating Maternal Mortality Guidance Notes for Potential Users. 1997 WHO/RHT/97.28 UNICEF/EPP/97.1.

19. Benedetti TJ, Starzyk $P$ and Frnst F Maternal deaths in Washington State. Obstet Gyneco/ 1985; 66: 99-101.

20. Trussell $J$ and Rodriguez G. A note on the sisterhood estimator of maternal mortality. Stud Fam Plann 1990; 21: 344-346.

21. Le Bacq $F$ and Rietsema A. High maternal mortality levels and additional risk from poor accessibility in two districts of Nothern Province, Zambia. Int J Epidemiol 1997; 2357-63.

22. Thaddeus $S$ and Maine D. Too far to walk: matemal mortality in context. Soc Si Med 1994; 38: 10911110.
23. Shiferaw $T$ and Tassema F. Maternal mortality in rural communities of Illubabor, Ethiopia. Ethiop Med J 1993; 31: 239-249.

24. Chiphangwi JD, Zamaere TP, Graham WJ, Duncan B, Kenyon T and Chinyama R. Maternal mortality in the Thyolo district in Southern Malawi. E Afr Med J 1992; 69: 675-679.

25. Danel I, Graham W, Stupp P and Castillo P. Applying the Sisterhood method for estimating maternal mortality to a health facility-based sample: a comparison with results from a household based sample. Int J Epidemiol 1996; 25: 1017-22.

26. Granja AC, Zacarias E and Bergstrom S. Violent deaths: the hidden face of maternal mortality. $\mathrm{BrJ}$ Obstet Gynaeco/ 2002; 109: 5-8.

27. Smith JB, Fortney JA, Wong E, Amatya R, Coleman $\mathrm{NA}$ and de Graft JJ. Estimates of the maternal mortality ratio in two districts of the Brong-Ahafo region, Ghana. Bull World Health Org 2000; 79: 400408.

28. Vork FC, Kyanamina $\mathrm{S}$ and van Roosmalen J. Maternal mortality in rural Zambia. Acta Obstet Gyneco/ Scand 1997; 76: 646-650.

29. Orach CG. Maternal mortality estimated using the Sisterhood method in Gulu district, Uganda. Trop Doc 2000, 30: 72-74.

30. Hernandez B, Chirinos J, Romero $M$ and Langer A. Estimating maternal mortality in rural areas of Mexico. Obstet Gynecol 1994; 46: 285-289.

31. Mace R and Sear R. Maternal mortality in a Kenyan pastoralist population. Int J Gytervi Obster 1996; 54 : 137-141.

32. Oosterhuis JW. Estimating maternal mortality by sisterhood method in rural Zimbabwe. Trop Doc 1993; 23: 357-363.

33. Schuitemaker N, van Roosmalen J, Dekker G, van Dongen P,van Geijn $\mathrm{H}$ and Bennebroek $\mathrm{G}$. Underreporting of maternal mortality in the Netherlands. Obstet Gynecol 1997; 90: 78-81. 